\title{
Effect of Online Cosmetics Information on Brand Trust and Continuous Purchasing Intentions Online
}

\author{
Byoung Su Kim ${ }^{1,2}$, Jung Min Lee ${ }^{3}$, Sungkwan $\mathrm{An}^{1 *}$ \\ ${ }^{1}$ Department of Cosmetics Engineering, Konkuk University, Seoul, Korea \\ ${ }^{2}$ Masstige Strategic \& Planning Team, LG Household \& Health Care, Seoul, Korea \\ ${ }^{3}$ Nature Blue Inc., Incheon, Korea
}

*Corresponding author: Sungkwan An, Department of Cosmetics Engineering, Konkuk University, 120 Neungdong-ro, Gwangjin-gu, Seoul 05029, Korea

Tel.: +82 24504054

Fax: +82 5027702278

Email: ansungkwan@konkuk.ac.kr

Received July 18, 2021

Revised August 18, 2021

Accepted September 17, 2021

Published September 30, 2021

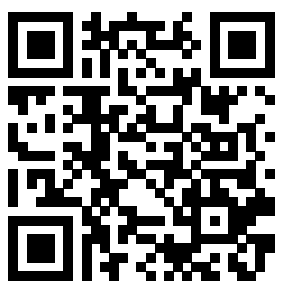

\begin{abstract}
Purpose: This study aims to analyze the impact of online cosmetics information, brand trust, and continuous purchasing behavior through in-depth research between brands, including purchase intentions and changes in perception of online shopping for cosmetics brands. Methods: A total of 1,300 surveys were distributed online in the last six months, excluding unfaithful respondents and missing values, and statistical processing was conducted using the IBM Statistical Package for the Social Science (SPSS) 22.0 and Amos 21.0. Results: This study analyzed the relationship between eight variables of reliability, positive emotion, negative emotion, purchase credibility, purchase intent, brand attitude, brand information, and information credibility. The results indicated that the higher the positive emotion, the higher the brand information, purchase intention, information reliability, purchase reliability, and brand attitude. Findings also suggested that the higher the negative emotion, the lower the intention of purchase, information reliability, purchase reliability, and brand attitude. The most influential factor of negative emotion was information reliability. The results of the reliability analysis demonstrated that higher reliability increased brand information, purchase intention, information reliability, purchase reliability, and brand attitude; reliability had the greatest impact on information reliability. Conclusion: When providing online cosmetics brand information, marketers need to strategize regarding brand advertising considering the online and mobile environment and user characteristics, actively proposing and managing contents and advertising that can effectively deliver the main ingredients and effects of non-advertising brand products and continuously provide objective and reliable cosmetics brand information.
\end{abstract}

Keywords: Brand information, Cosmetics, Online cosmetics information, Online purchases, Trust

\section{Introduction}

\section{1. 온라인 쇼핑 및 온라인 화장품 시장 동향}

국내 온라인 쇼핑 산업은 인터넷 이용 환경의 급격한 발전을 거듭 해 왔으며(Kim, 2012), 인터넷은 정보 검색뿐만 아니라 기업의 마 케팅 활동에 이용되기도 하며 거대한 정보 네트워크로 전 세계와 연 결되어 있어 빠르고도 신속한 커뮤니케이션을 가능하게 한다(Ju \& $\mathrm{Ahn}, 2010)$. 또한 인터넷의 확산과 함께 등장한 온라인 쇼핑몰은 소 비자들의 생활 패턴과 쇼핑 방식까지 변화시키면서 온라인상의 화장
품 구매가 증가하여 여러 소비자층이 온라인 쇼핑몰을 경험하고 있 다(Park \& Kim, 2008). 온라인쇼핑시장의 급성장과 관련 유통시장 의 변화, 온라인 비대면 중심의 유통환경의 변화는 비단 각종 기술의 발전에 기인한 것임과 동시에 오늘날 영민한 소비자들의 소비성향의 변화에도 그 원인을 찾을 수 있을 것이다(Moon, 2021) 이러한 온라 인 쇼핑의 거래액을 보면 거래액 기준 2019년 134조 5830억원이며, 이는 전년대비 $18.3 \%$ 증가한 것이다(Jeong, 2020). 온라인 쇼핑에서 의 화장품의 성장은 기존 판매 방식인 카운슬링과 제품 테스트를 통 한 대면 중심의 판매 및 구매 방식이 익숙한 일반적인 상식을 크게 웃 
도는 결과라 할 수 있다. 인터넷을 사용하여 쇼핑, 정보 탐색 등의 다 양한 경험과 체험을 통해 즐거움을 추구하거나 이러한 경향이 점진적 으로 확산 되면서 동일한 관심사와 가치를 공유하는 온라인내 소통 이 활성화되고 있다(Cho \& Eom, 2012). 인터넷 사용이 보편화 되면 서 온라인상의 다양한 커뮤니티 형성이 가능해졌으며, 새로운 커뮤 니케이션 수단으로 활용 되어지고 있다(Kwon \& Lee, 2018). 이러한 온라인을 통한 정보 공유는 자연스럽게 온라인 화장품 브랜드 제품에 대한 포괄적 정보에 대한 관심과 탐색이 증가한다고 보여진다. 온라 인을 통한 화장품 판매처는 화장품외 여러 상품을 일괄 구매할 수 있 는 종합몰과 주된 상품군만을 구성하여 판매하는 전문몰로 나눌 수 있으며 유통 경로에 따라 온라인을 통해서만 상품을 판매하는 온라인 전용몰, 온라인을 통한 상거래뿐 아니라 오프라인 판매를 병행하는 온라인·오프라인 병행몰로 나눌 수 있다(Kim \& Oh, 2018). 최근에는 온라인에서만 판매하고 있는 온라인전용 브랜드 화장품이 생겨나면 서 온라인 거래의 전문성을 강화하고 있다(Kim \& Oh, 2018). 유통 채널별 기초화장품 구매행동 연구에 따르면(Jeong, 2018), 선호하는 유통채널을 분석한 결과 전반적으로 온라인 유통채널의 선호도가 가 장 높았고, 백화점, 로드샵 순으로 나타났다. 이러한 온라인 화장품 구매시 주요 소비자들의 불만사항으로는 온라인에서 확인된 상품의 내용이나 정보가 인터넷 상에서 본 것과 다르다는 점이며, 이는 화장 품의 색상, 성분등의 정보를 가능한 정확히 제공하는 것이 매우 중요 하다(Lee \& Kim, 2006). 또한 화장품 온라인 쇼핑시 온라인 구전 정 보의 방향성이 소비자 구매의도에 미치는 영향에서 온라인 화장품
구매시 온라인 구전 정보, 즉 상품 사용 후기를 참고하는 정도가 매 우 높고, 사용후기를 읽고 구매의도를 갖으며, 온라인 구전 정보, 사 용후기에 대한 긍정적인 내용을 볼 때 구매의도를 높게 지각 한다고 하였다(Son \& Eo). 이러한 변화는 화장품을 단순히 피부를 청결, 미 화하여 용모를 밝게 변화시키는 기능뿐 아니라 피부 결점을 개선 시 키는 기능까지 요구되고 있는 특성들이 반영된 것이다(Kim \& Han, 2018). 온라인 쇼핑에서 판매자 정보와 상품정보에 대해서는 보다 자 세하게 설명하는 것이 온라인 에서의 구매의도에 긍정적인 영향을 주 고 있다는 것은 선행 연구에서 다루어 졌다(Joh, 2007). 하지만 상품 의 어떠한 정보들이 구매의도에 긍정적인 영향을 주는지에 대한 연구 는 더 필요한 상태이다. Kang \& $\operatorname{Sin}$ (2006)은 화장품의 구매결정 요 인을 분석함에 있어 화장품 소비자의 소비성향은 5 가지 성향(자원약 성향, 계획구매성향, 유행 추구성향, 과시소비성향, 충동구매성향)으 로 분류하였고, 이를 구매결정요인에서 인구 통계학적 변수(결혼여 부, 연령, 직업, 1 회 구입비용등)로 구분하여 분석하였다. 결과에 따 르면 브랜드 명성도 뿐 아니라 제품의 전반적인 품질을 신중히 고려 하고 다양한 정보들을 반영하여 합리적인 태도로 구매하는 경향이 있 다고 하였다. 이 연구는 오프라인 매장을 대상이었으나, 온라인에서 도 이와 유사한 화장품 구매의도에 영향을 주는 제품의 성분, 품질, 효능/효과, 가격, 용기 및 포장 디자인과 브랜드 이미지 등 이러한 차 이와 특성에 대해서는 연구가 활발히 이루어지지 않고 있다. 이와 같 은 상황을 볼 때 온라인 쇼핑의 화장품 시장에 대한 보다 심도 있는 연구와 분석이 필요한 상황이며, 더욱이 온라인 쇼핑 화장품 시장은

Table 1. General characteristics of research participants

\begin{tabular}{|c|c|c|c|}
\hline & Item & $\mathrm{N}$ & $\%$ \\
\hline \multirow{2}{*}{ Grader } & Male & 353 & 29.5 \\
\hline & Female & 844 & 70.5 \\
\hline \multirow{6}{*}{ Age group } & $19-20$ & 54 & 4.5 \\
\hline & $20-29$ & 81 & 6.8 \\
\hline & $30-39$ & 399 & 33.3 \\
\hline & $40-49$ & 432 & 36.1 \\
\hline & $50-59$ & 98 & 8.2 \\
\hline & $60-69$ & 133 & 11.1 \\
\hline \multirow{5}{*}{ Address } & Metropolitan area & 745 & 62.2 \\
\hline & Central region & 100 & 8.4 \\
\hline & Honam region & 68 & 5.7 \\
\hline & Gyeongsang region & 266 & 22.2 \\
\hline & Gangwon region & 18 & 1.5 \\
\hline \multirow{2}{*}{ Marital status } & Single & 561 & 46.9 \\
\hline & Married & 636 & 53.1 \\
\hline \multirow{4}{*}{ Education } & High school graduate & 167 & 14.0 \\
\hline & College student/ Graduate & 148 & 12.4 \\
\hline & University student/ Graduate & 715 & 59.7 \\
\hline & Graduate degree or Higher & 167 & 14.0 \\
\hline
\end{tabular}


지속적으로 시장규모가 성장하면서 세분화, 다양화 됨에 따라 이에 대한 온라인에서의 화장품 브랜드 정보와 관련된 다양한 연구와 분석 이 필요하다.

\section{2. 연구의 목적 및 필요성}

본 연구는 온라인 쇼핑에서 화장품에 대한 정보는 브랜드를 중심 으로 운영 되고 있으며, 이러한 브랜드의 주요 정보라도 볼 수 있는 제품 관련 성분, 가격, 효능, 효과 및 사용후기 등의 폭 넓은 브랜드 정보가 노출 되어 있고, 이러한 정보들이 브랜드 신뢰와 온라인에서 의 지속적인 구매 활동에 어떠한 영향을 주는지에 대한 고찰 하고자 한다. 이러한 온라인 쇼핑 화장품 브랜드 관련 정보들을 통해 각 브 랜드 제품의 특성을 비교하면서 온라인 구매 고객의 패턴, 인식 변화 등 구매와 브랜드간의 심층적 연구 및 체계화하여 온라인 화장품 정 보가 브랜드 신뢰 및 온라인에서의 지속적 구매행동에 미치는 영향에 대해 분석하고자 한다. 이를 통해 온라인 쇼핑 화장품 채널 사업에 대한 정부 및 기업에 유용한 정보를 제공하는 데 연구의 궁극적인 목 적이 있다.

\section{Methods}

\section{1. 연구대상 및 자료 수집}

본 연구를 위한 자료수집은 최근 6 개월간 온라인을 통해 화장품을 구입한 경험이 있는 사용자를 주요 대상으로 하였다. 설문지는 온라 인을 통한 설문을 통해 총 1,300 부가 배부되었고 이들 중 온라인으로 화장품을 구입한 경험이 없는 사용자와 불성실한 응답자, 결측값을 제외하고 총 1,197 부를 최종 분석하여 결과는 Table 1 과 같다.

\section{2. 측정 내용}

본 연구는 설문지를 통해 연구대상의 온라인 화장품 정보에 대한 구매 신뢰성, 구매의도, 브랜드 태도, 브랜드 정보, 정보 신뢰도에 대 해 신뢰성, 긍정적 감정, 부정적 감정 등을 분석하였으며 이를 위해 설문지는 총 57 문항의 측정항목으로 구성 되어져 있으며, 본 설문조 사를 위해 5 점 리커트 척도와 인구통계적 특성 측정을 사용 하였다.

\section{3. 분석 방법}

본 연구에서는 회수 된 설문지의 통계처리는 데이터 코딩 과정을 거 친 다음 Statistical Package for Social Science (SPSS) 22.0과 Amos 21.0 을 사용하여 다음과 같은 방법으로 실증 분석을 실시하였다.

첫째, 설문 응답자들의 인구통계학적 특성과 일반적 특성을 분석 하기 위해 빈도분석(frequency analysis)을 실시하였다.

둘째, 측정도구들에 대한 정규성을 파악하고자 기술통계분석을 실 시하였다.

셋째, 설문 항목들에 대한 개념적 타당성을 검토하기 위해 탐색적 요인분석(factor analysis)을 실시하였다. 또한 측정 변수들의 내적 일관성을 검증하기 위해 신뢰도분석(reliability analysis)을 실시하였 다.

넷째, 탐색적 요인분석에서 확인된 요인들에 대해 확인적 요인분 석을 실시하여 각 측정변수들의 집중 타당성과 잠재변수의 집중 타당 성을 확인하였다.

다섯째, 각 측정변수들 간의 관계를 파악하기 위하여 이변량 상관 관계분석(correlation Analysis)을 실시하였으며 판별타당성을 파악 하기 위하여 AVE 및 개념신뢰도 분석을 실시하였다.

\section{Results and Discussion}

\section{1. 타당성 및 신뢰도 검증}

전체 수거 설문지 1,197 부를 분석대상으로 하였으며 측정도구 에 대한 개념 타당성을 파악하고 내용의 타당성을 확보하기 위하여 SPSS $22.0 \mathrm{~K}$ 를 이용하여 요인분석을 실시하였다. 요인분석은 측정 지표의 실제 측정결과가 본래 의도된 이론적 개념과 부합하는지를 평가하는 일반적인 분석방법으로 가장 보편적으로 이용되고 있다. 요인분석에서 요인을 추출하는 방법으로는 일반적으로 주성분분석 (principal component)에 의한 방법과 공통요인분석(common factor analysis)에 의한 방법이 있는데, 본 연구에서는 주성분 분석을 사용 하여 조사한 결과를 나타났다. 일반적으로 요인추출은 요인이 설명 할 수 있는 분산의 양을 뜻하는 아이겐(eigen) 값을 기준으로 하여 아 이겐 값이 1.0 이상인 요인들을 추출한다. 여기서 아이겐 값이 1.0 이 라는 의미는 변수하나 정도의 분산을 축약하고 있다는 의미이다. 요 인 적재치(factor loading)는 0.40 이상인 경우를 통계적으로 유의한 것으로 판단되고, 요인간의 상관관계인 다중 공선성을 제거하기 위 하여 직각회전(varimax)방식으로 나타냈다.

확인적 요인분석은 각 측정변수들의 집중 타당성과 잠재변수의 집중 타당성 및 판별 타당성 등을 검증하는 단계를 거쳐서 진행하였 다. 타당성 평가를 위해 탐색적 요인분석에 이어 확인적 요인분석을 외생변수와 내생변수로 나누어 $\mathrm{AMOS} 21.0$ 의 측정모형을 이용하 여 실시하였다. 확인적 요인 분석은 탐색적 요인분석과 대비되는 요 인분석의 한 방법으로 연구자가 자료 내부에 숨겨져 있는 이론적 구 조에 대한 정보를 사전에 알고 있어서, 이 이론적 구조를 확인하고 자 할 때 사용하는 방법이다. 이는 신뢰성 검증이 내적 일관성을 가 정하지만 검증하지 못하기 때문에 널리 이용되고 있다. 적합도를 평 가하기 위하여 goodness of fit index (GFI), adjusted goodness of fit index (AGFI), root mean square residual (RMR), normed fit index (NFI), $\chi^{2}, \chi^{2}$ 의 $p$ 값을 이용하였다. 신뢰성이란 동일한 개념 에 대하여 반복적으로 측정하였을 때 나타나는 측정값들의 분산을 의 미한다.

본 연구에서는 내적 일관성을 측정 하기 위해 크론바 알파 
Table 2. Descriptive statistics analysis

\begin{tabular}{|c|c|c|c|c|c|c|}
\hline & Item & Questionnaire items & Average & $\begin{array}{l}\text { Standard } \\
\text { deviation }\end{array}$ & Skewness & Kurtosis \\
\hline \multirow{13}{*}{$\begin{array}{l}\text { Independent } \\
\text { variables }\end{array}$} & Reliability 1 & $\begin{array}{l}\text { I trust the information shared by influencers among other online } \\
\text { cosmetics information providers. }\end{array}$ & 3.46 & 0.76 & -0.128 & 0.536 \\
\hline & Reliability 2 & I trust whoever the seller is that is selling online. & 3.46 & 0.76 & -0.105 & 0.491 \\
\hline & Reliability 3 & I trust all cosmetics-related information I find online. & 3.50 & 0.80 & -0.039 & 0.204 \\
\hline & Reliability 4 & $\begin{array}{l}\text { I think the information about cosmetics I found online is recent } \\
\text { information. }\end{array}$ & 3.51 & 0.80 & -0.042 & 0.206 \\
\hline & Positive feelings 1 & $\begin{array}{l}\text { I can easily understand the contents of online cosmetics } \\
\text { advertisement. }\end{array}$ & 3.27 & 0.89 & 0.000 & 0.002 \\
\hline & Positive feelings 2 & I can easily find information on new cosmetics products online. & 3.22 & 0.95 & 0.012 & -0.349 \\
\hline & Positive feelings 3 & I like online cosmetics commercial videos. & 3.18 & 0.94 & 0.055 & -0.274 \\
\hline & Positive feelings 4 & I enjoy buying cosmetics online. & 3.22 & 0.94 & 0.012 & -0.251 \\
\hline & Positive feelings 5 & I am happy to buy cosmetics online. & 3.20 & 0.95 & 0.034 & -0.354 \\
\hline & Negative feelings 1 & I do not watch online cosmetics commercial videos. & 2.23 & 0.88 & 0.517 & 0.267 \\
\hline & Negative feelings 2 & I do not trust the ingredients of online cosmetics advertisements. & 2.38 & 0.87 & 0.259 & 0.002 \\
\hline & Negative feelings 3 & I do not trust the effects of cosmetics online. & 2.33 & 0.86 & 0.243 & -0.059 \\
\hline & Negative feelings 4 & $\begin{array}{l}\text { Buying cosmetics online is a bit more inconvenient than buying } \\
\text { them at the store. }\end{array}$ & 2.37 & 0.86 & 0.263 & 0.062 \\
\hline \multirow{25}{*}{$\begin{array}{l}\text { Dependent } \\
\text { variables }\end{array}$} & Purchase reliability 1 & I trust reviews of efficacy online. & 2.97 & 0.89 & 0.031 & -0.119 \\
\hline & Purchase reliability 2 & I am fond of online cosmetics advertisements. & 3.39 & 0.78 & -0.367 & 0.142 \\
\hline & Purchase reliability 3 & I look up reviews of the effects of cosmetics I found online. & 3.19 & 0.86 & -0.176 & 0.211 \\
\hline & Purchase reliability 4 & I will continue to buy cosmetics online. & 3.03 & 0.91 & -0.222 & 0.137 \\
\hline & Purchase reliability 5 & $\begin{array}{l}\text { I want to recommend buying cosmetics online to people around } \\
\text { me. }\end{array}$ & 3.24 & 0.85 & -0.224 & 0.496 \\
\hline & Intention of purchase 1 & I refer to the reviews when purchasing online cosmetics. & 3.20 & 0.92 & 0.016 & -0.168 \\
\hline & Intention of purchase 2 & I look online for reviews of the benefits/effects of purchasing. & 3.27 & 0.88 & -0.096 & 0.109 \\
\hline & Intention of purchase 3 & $\begin{array}{l}\text { I compare the prices of products when purchasing cosmetics } \\
\text { online. }\end{array}$ & 3.37 & 0.74 & 0.124 & 0.342 \\
\hline & Intention of purchase 4 & $\begin{array}{l}\text { When purchasing online cosmetics, I compare the promotional } \\
\text { events of products. }\end{array}$ & 3.25 & 0.93 & -0.079 & -0.097 \\
\hline & Intention of purchase 5 & $\begin{array}{l}\text { I compare the reviews of products when purchasing online } \\
\text { cosmetics. }\end{array}$ & 3.28 & 0.90 & -0.125 & 0.037 \\
\hline & Brand attitude 1 & I have a cosmetic brand that I like. & 3.47 & 0.82 & -0.135 & 0.141 \\
\hline & Brand attitude 2 & When I buy cosmetics online, I see effects before brands. & 3.30 & 0.84 & -0.418 & 0.600 \\
\hline & Brand attitude 3 & $\begin{array}{l}\text { When I buy cosmetics online, I usually look at ingredients rather } \\
\text { than brands. }\end{array}$ & 3.26 & 0.79 & 0.197 & 0.145 \\
\hline & Brand attitude 4 & $\begin{array}{l}\text { When I bought cosmetics online, I saw a brand advertisement } \\
\text { and bought them. }\end{array}$ & 3.23 & 0.79 & 0.008 & 0.093 \\
\hline & Brand attitude 5 & When I buy cosmetics online, I usually buy certain brands. & 3.43 & 0.79 & -0.332 & 0.453 \\
\hline & Brand information 1 & I look up my favorite brand information online. & 2.96 & 0.96 & 0.006 & -0.449 \\
\hline & Brand information 2 & I look online for my favorite brand reviews. & 2.96 & 0.96 & 0.029 & -0.357 \\
\hline & Brand information 3 & $\begin{array}{l}\text { I look online for the efficacy/effectiveness of my favorite } \\
\text { cosmetics brand. }\end{array}$ & 2.99 & 0.98 & -0.022 & -0.429 \\
\hline & Brand information 4 & I look for my favorite brand products online. & 2.99 & 0.96 & 0.026 & -0.312 \\
\hline & Brand information 5 & $\begin{array}{l}\text { When I buy cosmetics online, I look for my favorite brand } \\
\text { ingredients. }\end{array}$ & 3.40 & 0.77 & 0.033 & 0.155 \\
\hline & Information reliability 1 & Online cosmetics advertisements help me when I buy. & 3.34 & 0.85 & -0.175 & 0.060 \\
\hline & Information reliability 2 & I trust the ingredients shown in online cosmetics advertisements. & 3.38 & 0.70 & -0.053 & 1.076 \\
\hline & Information reliability 3 & I trust reviews of cosmetics ingredients online. & 3.42 & 0.69 & 0.218 & 0.228 \\
\hline & Information reliability 4 & I trust the effectiveness of online cosmetics advertising. & 3.41 & 0.76 & -0.103 & 0.572 \\
\hline & Information reliability 5 & I trust the effectiveness of online cosmetics reviews. & 3.27 & 0.69 & 0.205 & 0.512 \\
\hline
\end{tabular}


(Cronbach's alpha)계수를 이용하여 신뢰도를 측정하였다. Nunnally (1978)는 탐색적인 연구 분야에서는 알파값이 0.60 이상이면 충분하 고, 기초연구 분야에서는 0.80 , 그리고 중요한 결정이 요구되는 응용 연구 분야에서는 0.90 이상이어야 한다고 주장하고 있다. 또한 $\mathrm{Van}$ de Ven \& Ferry (1980)도 조직단위의 분석수준에서 일반적으로 요 구 되어지는 알파 값은 0.60 이상이면 측정도구의 신뢰성에는 별 문 제가 없는 것으로 일반화 하고 있다. 설문문항들에 대한 평균 및 표 준편차 값은 Table 2 와 같다. 신뢰성에서는 신뢰성4(나는 온라인에서 찾은 화장품 관련 정보 최근 정보라고 생각한다)가 3.51 로 가장 높은 평균을 보여주었으며 긍정적 감정에서는 긍정적 감정1 (나는 온라인 화장품 광고 컨텐츠는 이해하기 쉽다)가 3.27 , 부정적 감정에서는 부 정적 감정2 (나는 온라인 화장품 광고의 성분내역을 신뢰하지 않는
다)가 2.38로 가장 높은 평균을 보여주었다. 구매신뢰도에서는 구매 신뢰도2 (나는 온라인 화장품 광고에 호감을 느낀다)가 3.39 , 구매의 도에서는 구매의도3 (나는 온라인 화장품 정보 구매 시 제품의 가격 을 비교한다)이 3.37 , 브랜드태도에서는 브랜드태도1 (나는 내가 좋 아하는 화장품 브랜드가 있다)이 3.47 , 브랜드 정보에서는 브랜드 정 보5(나는 온라인에서 화장품 구매시 내가 좋아하는 브랜드 성분을 찾 아 본다)가 3.40 , 정보신뢰도의 경우 정보신뢰도3 (나는 온라인에서 화장품의 성분의 후기를 신뢰한다)가 3.42 로 가장 높은 평균을 보여 주었다. 또한, 측정항목에 대한 왜도, 첨도의 경우 왜도(skewness)는 자료의 분포모양이 어느 쪽으로 얼마만큼 기울어져 있는가를 나타내 며 일반적으로 왜도의 절대값이 1 보다 큰 경우에는 정규분포에서 크 게 벗어난 것으로 간주한다(Sung et al., 2011). 첨도(kurtosis)는 자

Table 3. Investigating factor analysis results for measuring tools

\begin{tabular}{|c|c|c|c|c|c|c|c|c|}
\hline \multirow{2}{*}{ Survey Items } & \multicolumn{8}{|c|}{ Components } \\
\hline & 1 & 2 & 3 & 4 & 5 & 6 & 7 & 8 \\
\hline Positive feelings 5 & 0.903 & & & & & & & \\
\hline Positive feelings 3 & 0.889 & & & & & & & \\
\hline Positive feelings 2 & 0.875 & & & & & & & \\
\hline Positive feelings 4 & 0.853 & & & & & & & \\
\hline Positive feelings 1 & 0.504 & & & & & & & \\
\hline Brand Information 1 & & 0.896 & & & & & & \\
\hline Brand Information 4 & & 0.893 & & & & & & \\
\hline Brand Information 2 & & 0.887 & & & & & & \\
\hline Brand Information 3 & & 0.859 & & & & & & \\
\hline Negative feelings 3 & & & -0.914 & & & & & \\
\hline Negative feelings 2 & & & -0.912 & & & & & \\
\hline Negative feelings 4 & & & -0.911 & & & & & \\
\hline Negative feelings 1 & & & -0.775 & & & & & \\
\hline Reliability 4 & & & & 0.871 & & & & \\
\hline Reliability 3 & & & & 0.861 & & & & \\
\hline Reliability 1 & & & & 0.849 & & & & \\
\hline Reliability 2 & & & & 0.840 & & & & \\
\hline Intention of purchase 2 & & & & & 0.872 & & & \\
\hline Intention of purchase 5 & & & & & 0.855 & & & \\
\hline Intention of purchase 4 & & & & & 0.699 & & & \\
\hline Intention of purchase 1 & & & & & 0.614 & & & \\
\hline Information reliability 3 & & & & & & 0.776 & & \\
\hline Information reliability 2 & & & & & & 0.710 & & \\
\hline Information reliability 4 & & & & & & 0.704 & & \\
\hline Information reliability 5 & & & & & & 0.668 & & \\
\hline Purchase reliability 4 & & & & & & & 0.766 & \\
\hline Purchase reliability 1 & & & & & & & 0.743 & \\
\hline Purchase reliability 3 & & & & & & & 0.641 & \\
\hline Purchase reliability 5 & & & & & & & 0.601 & \\
\hline Brand attitude 1 & & & & & & & & 0.764 \\
\hline Brand attitude 5 & & & & & & & & 0.762 \\
\hline Brand attitude 2 & & & & & & & & 0.713 \\
\hline Brand attitude 4 & & & & & & & & 0.553 \\
\hline Eigenvalue & 4.183 & 3.720 & 3.684 & 3.558 & 3.048 & 2.852 & 2.729 & 2.573 \\
\hline Description variance (\%) & 12.676 & 11.273 & 11.165 & 10.780 & 9.235 & 8.641 & 8.271 & 7.797 \\
\hline Cumulative variance (\%) & 12.676 & 23.949 & 35.114 & 45.894 & 55.129 & 63.770 & 72.041 & 79.838 \\
\hline Cronbach's alpha & 12.676 & 0.954 & 0.957 & 0.954 & 0.896 & 0.839 & 0.855 & 0.813 \\
\hline
\end{tabular}


료의 분포모양이 위로 뽀족한 정도를 나타내는 것으로 첨도의 절대값 이 7보다 작아야 정상분포를 이룬다고 볼 수 있다. 이러한 기준을 적 용할 때 본 연구에서 사용된 데이터들은 모두 왜도, 첨도 기준을 충 족시키는 것으로 나타나 정규분포를 가정한다는 것을 확인할 수가 있 었다.

\section{2. 측정도구에 대한 탐색적 요인분석}

본 연구에서 선정한 요인인 신뢰성, 긍정적 감정, 부정적 감정, 구 매신뢰도, 구매의도, 브랜드태도, 브랜드 정도, 정보신뢰도에 대한
요인분석 결과 8 개로 Table 3 과 같다. 아이겐 값은 2.573 에서 4.183 로 모두가 1.0 을 상회하는 것으로 나타나 모든 요인들이 명확히 분 류되었다. 누적분산은 $79.838 \%$ 로 나타났고, 요인적 채치가 0.4 보 다 크게 나타나 동일 요인의 측정변수간의 집중 타당성과 판별 타당 성이 모두 검증되었다. 또한, $\mathrm{KMO}$ 의 수치는 0.886 , Bartlett의 구 형성 검증에서는 카이제곱 값이 $48932.2(\mathrm{df}=528, p=0.000)$ 으로 파악되었다. 세부적인 탐색적 요인분석을 실시한 결과 긍정적 감정 은 모두 5 개의 설문항목들로 구성이 되어졌으며 아이겐 값(eigenvalue)은 4.183 , 설명분산은 $12.676 \%$ 로 나타나 긍정적 감정요인으

Table 4. Confirmative factor analysis results

\begin{tabular}{|c|c|c|c|c|c|c|}
\hline & Item & & Estimate & S.E. & C.R. & $p$ \\
\hline Positive feelings 1 & $<--$ & \multirow{5}{*}{ Positive feelings } & 1.000 & & & \multirow{2}{*}{${ }_{* * *}^{* *}$} \\
\hline Positive feelings 4 & $<--$ & & 1.427 & 0.052 & 27.415 & \\
\hline Positive feelings 2 & $<--$ & & 1.556 & 0.054 & 28.915 & $* * *$ \\
\hline Positive feelings 3 & $<--$ & & 1.510 & 0.053 & 28.661 & *** \\
\hline Positive feelings 5 & $<--$ & & 1.609 & 0.059 & 27.038 & $* * *$ \\
\hline Brand information 3 & $<--$ & \multirow{4}{*}{ Brand information } & 1.000 & & & \multirow{4}{*}{$\begin{array}{l}{ }_{* * *} \\
{ }_{* * *} \\
* * * *\end{array}$} \\
\hline Brand information 2 & $<--$ & & 1.168 & 0.029 & 40.285 & \\
\hline Brand information 4 & $<--$ & & 1.008 & 0.016 & 62.989 & \\
\hline Brand information 1 & $<--$ & & 1.143 & 0.026 & 44.469 & \\
\hline Negative feelings 1 & $<--$ & \multirow{4}{*}{ Negative feelings } & 1.000 & & & \multirow{3}{*}{$\begin{array}{l}{ }^{* * *} \\
* * *\end{array}$} \\
\hline Negative feelings 4 & $<--$ & & 1.336 & 0.036 & 36.833 & \\
\hline Negative feelings 2 & $<--$ & & 1.342 & 0.037 & 36.594 & \\
\hline Negative feelings 3 & $<--$ & & 1.253 & 0.030 & 41.118 & $* * *$ \\
\hline Reliability 2 & $<--$ & \multirow{4}{*}{ Reliability } & 1.000 & & & \multirow{4}{*}{$\begin{array}{l}* * * \\
* * * \\
* * *\end{array}$} \\
\hline Reliability 1 & $<--$ & & 1.000 & 0.007 & 135.318 & \\
\hline Reliability 3 & $<--$ & & 0.814 & 0.020 & 40.642 & \\
\hline Reliability 4 & $<--$ & & 0.823 & 0.020 & 41.792 & \\
\hline Intention of purchase 1 & $<--$ & \multirow{4}{*}{ Intention of purchase } & 1.000 & & & \multirow{4}{*}{$\begin{array}{l}{ }^{* * *} \\
{ }_{* * *} \\
* * *\end{array}$} \\
\hline Intention of purchase 4 & $<--$ & & 1.189 & 0.043 & 27.532 & \\
\hline Intention of purchase 5 & $<--$ & & 1.666 & 0.070 & 23.707 & \\
\hline Intention of Purchase 2 & $<--$ & & 1.647 & 0.069 & 23.757 & \\
\hline Intention of purchase 5 & $<--$ & \multirow{4}{*}{ Information reliability } & 1.000 & & & \multirow{4}{*}{$\begin{array}{c}* * * \\
* * * \\
* * * \\
*\end{array}$} \\
\hline Information reliability 4 & $<--$ & & 1.148 & 0.051 & 22.493 & \\
\hline Information reliability 2 & $<--$ & & 1.141 & 0.047 & 24.033 & \\
\hline Information reliability 3 & $<--$ & & 1.179 & 0.047 & 24.950 & \\
\hline Purchase reliability 5 & $<--$ & \multirow{4}{*}{ Purchase reliability } & 1.000 & & & \multirow{4}{*}{$\begin{array}{l}* * * \\
* * * \\
* * *\end{array}$} \\
\hline Purchase reliability 3 & $<--$ & & 1.038 & 0.039 & 26.397 & \\
\hline Purchase reliability 1 & $<--$ & & 1.033 & 0.041 & 24.944 & \\
\hline Purchase reliability 4 & $<--$ & & 1.080 & 0.042 & 25.516 & \\
\hline Brand attitude 4 & $<--$ & \multirow{4}{*}{ Brand attitude } & 1.000 & & & \multirow{4}{*}{$\begin{array}{l}\text { *** } \\
{ }_{* * *} \\
\text { *** }\end{array}$} \\
\hline Brand attitude 2 & $<--$ & & 1.116 & 0.050 & 22.158 & \\
\hline Brand attitude 5 & $<--$ & & 0.992 & 0.048 & 20.821 & \\
\hline Brand attitude 1 & $<--$ & & 0.980 & 0.049 & 19.831 & \\
\hline
\end{tabular}

${ }^{* * *} p<0.001 ;$ C.R., critical ratio. 
로 선정하였으며 브랜드정보는 모두 4 개의 관련 문항들로 구성되었 으며 아이겐 값(eigen-value)은 3.720 , 설명분산은 $11.273 \%$ 로 나 타나 브랜드 정보 요인으로 선정을 하였다. 부정적감정에 대한 분 석의 결과 모두 4 개의 관련 문항으로 나타났으며 아이겐 값(eigenvalue)은 3.684 , 설명분산은 $11.165 \%$ 로 나타나 부정적 감정 요인으 로 선정하였으며 신뢰성에서는 모두 4 개의 관련 문항과 아이겐 값 (eigen-value)은 3.558 , 설명분산은 $10.780 \%$ 로 확인되었다. 구매의 도에 대한 탐색적 요인분석에서는 모두 4 개의 관련 문항으로 나타났 으며 아이겐 값(eigen-value)은 3.048 , 설명분산은 $9.235 \%$, 정보신 뢰도의 경우 4 개의 관련 문항과 아이겐 값(eigen-value)은 2.852 , 설 명분산은 $8.641 \%$, 구매신뢰도에서는 모두 4 개의 관련 문항과 아이 겐 값(eigen-value)은 2.729 , 설명분산은 $8.271 \%$ 로 나타나 본 연구 의 요인으로 선정을 하였다. 그리고 브랜드 태도에 대한 분석에서는 모두 4개의 관련 문항으로 구성되었으며 아이겐 값(eigen-value)은 2.573 , 설명분산은 $7.797 \%$ 로 나타나 브랜드 태도로 명명(naming) 하였다. 그리고 8 개 요인에 대한 신뢰도 분석의 결과 Cronbach alpha 값이 기준치인 0.6 이상으로 나와 측정도구의 타당성은 확보 가 되었다

\section{3. 측정도구에 대한 확인적 요인분석 결과}

전체 인과모형에 대한 구조 방정식 모형분석을 하기 이전에 측정 변수의 판별 타당성과 수렴 타당성은 탐색적 요인분석을 통해 어느 정도 확인되었으나, 측정항목에 대하여 요인별 단일차원성 확인 및 통계적 검증을 위하여 $\mathrm{AMOS} 21.0$ 을 이용하여 선행요인에 대한 확인 적 요인분석을 실시하였다. 선행요인들의 특성에 대한 확인적 요인 분석의결과 $\chi^{2}=3039.657, \mathrm{df}=458, \chi^{2}$ 에 대한 $p$ 값 $=0.000$, 기초적 합지수(goodness of fit index, GFI) $=0.872$, 조정적합지수(adjusted goodness of fit index, AGFI) $=0.844$, 비교 적합지수(comparative fit index, CFI)=0.947, 원소간 평균차이(root mean square residual, $\mathrm{RMR})=0.063$, 표준적합지수(normed fit index, NFI) $=0.938$, root mean square error or approximation, RMSEA) $=0.069$ 등과 같은 통계수치로 나타났다. 이와 같이 나타난 본 연구의 모형은 적합모형 의 지표들과 비교할 때 CFI지수가 0.947이며 GFI가 0.872로 권장치 이상이며, Chi-square값도 유의한 것으로 나타났다. 확인적 요인분 석 결과로서 구조모델 추정에 대한 기각비(critical ratio, C.R)의 크기 를 절대값이 1.96 이상 기준으로 해석하고자 할 경우 Table 4에서 보 는 것처럼 본 연구의 모형은 각 측정변수의 기각비(C.R)가 1.96 을 크 게 초과하고, 유의수준 $p<0.001$ 에서 유의한 것으로 나타났다. 그리 하여 Table 5 와 같이 집중 타당성이 있다고 판단된다.

\section{4. 판별타당성}

본 연구에서 선정된 변수들의 판별 타당도를 파악하기 위하여 아래의 수식을 참고하여 판별타당도 분석을 시행하였다. 판별타 당도 검증의 결과 판별타당도는 평균분산추출 (average variance extracted, $\mathrm{AVE}$ )과 개념들 간 상관계수 값을 이용하여 분석할 수 있 다. 구성개념들 간의 상관계수의 제곱값이 평균분산추출량 $(\mathrm{AVE})$ 을 초과하지 않으면 판별타당성을 지닌다(Fornell \& Laker, 1981). 즉 판별타당성 평가의 대상이 되는 각각의 평균분산 추출량과 그 둘 간 의 상관관계의 제곱을 비교하여 두 평균 분산추출량이 모두 상관관 계의 제곱보다 크면 그 두 대상 간에는 판별타당성이 있다고 할 수 있 다. 분산추출량은 측정오차에 의한 변량의 양과 관계에서 구성개념 이 잡아낸 변량의 양을 의미한다. 평균분산추출량은 Fornell \& Laker (1981)가 제안한 공식에 의하여 계산하였으며, 평균분산추출량은 일 반적으로 0.5 이상이면 집중타당성을 갖는 것으로 받아들이는데 이

Table 5. Model goodness-of-fit exponent

\begin{tabular}{|c|c|c|}
\hline Goodness-of-fit index & Evaluation criteria & Model fitting results \\
\hline Degrees of freedom (df) & $\begin{array}{l}\text { The number of available units of information after } \\
\text { which the parameter is estimated }\end{array}$ & 458 \\
\hline Chi-square statistics & - & 3039.657 \\
\hline Probability of significance $(p)$ & - & 0.000 \\
\hline Goodness-of-fit index GFI) & $>0.9$ Excellent, $>0.8$ Good & 0.872 \\
\hline Adjusted goodness-of-fit index (AGFI) & $>0.8$ Excellent, $>0.7$ Good & 0.844 \\
\hline Root mean square residual (RMR) & Min value & 0.063 \\
\hline Normed fit index (NFI) & $>0.9$ Excellent, >0.8 Good & 0.938 \\
\hline Tucker-Lewis index (TLI) & $>0.9$ Excellent, >0.8 Good & 0.939 \\
\hline Comparative fit index (CFI) & $>0.9$ Excellent, >0.8 Good & 0.947 \\
\hline Incremental fit index (IFI) & The closer to 1 , the better & 0.947 \\
\hline $\begin{array}{l}\text { Simplified basic compatibility index } \\
\text { (Parsimonious } \mathrm{CFI} \text { ) }\end{array}$ & $>0.7$ Excellent, >0.6 Good & 0.822 \\
\hline $\begin{array}{l}\text { Simple standard compliance index } \\
\text { (Parsimonious NFI) }\end{array}$ & $>0.7$ Excellent, >0.6 Good & 0.814 \\
\hline Approximate mean error square root (RMSEA) & $<0.1$ Adoption, <0.05 Optimal & 0.069 \\
\hline
\end{tabular}


는 항목들의 분산중 $1 / 2$ 은 construct에 의해 설명될 수 있어야 그 항목들을 수용할 가치가 있다는 것을 의미한다. 또한, Anderson \& Gerbing (1986)에 따르면 개념신뢰도는 0.7이상이면 집중타당도가 우수하다고 판단을 하였는데 이러한 기준에서 본 연구에서 사용된 요 인들이 개념신뢰도는 대부분 0.7 이상으로 나타나 집중타당성은 확보 가 되었다고 판단이 된다. 본 연구의 측정모형에서 사용된 구성개념 간의 평균분산추출량 및 개념신뢰도는 Table 6 과 같다. 구성개념들 간의 상관계수의 제곱값이 $\mathrm{AVE}$ 를 초과하지 않는 것으로 나타났기 때 문에 구성개념 간 판별타당성은 확보되었다고 할 수 있다. 본 연구에 서는 단일차원성이 입증된 각 연구단위별 척도들에 대하여 서로의 관
계가 어떠한 방향이며, 어느 정도의 관계를 갖는지를 알아보기 위하 여 먼저 상관관계 분석을 실시하였다. 상관관계 분석은 독립변인들 간의 상관관계를 파악하기 위해서 실시하였으며, 대부분 상관관계가 존재하는 것으로 나타났다. 또한 판별계수의 값도 일정수준인 0.5 이 상으로 나타나 판별 타당도에는 이상이 없다는 것을 알 수 있다.

\section{5. 전체 연구모형의 적합도 평가}

본 연구에서 선정한 요인 8개의 중요변수인 신뢰성, 긍정적 감 정, 부정적 감정, 구매신뢰도, 구매의도, 브랜드 태도, 브랜드 정 보, 정보신뢰도로 구성하였다. 연구모형에서 탐색적 요인분석을 통

\section{Table 6. Correlation and discrimination feasibility analysis results}

\begin{tabular}{|c|c|c|c|c|c|c|c|c|c|c|}
\hline Factor name & Average & $\begin{array}{l}\text { Standard } \\
\text { deviation }\end{array}$ & Reliability & $\begin{array}{l}\text { Positive } \\
\text { feelings }\end{array}$ & $\begin{array}{l}\text { Negative } \\
\text { feelings }\end{array}$ & $\begin{array}{l}\text { Purchase } \\
\text { reliability }\end{array}$ & $\begin{array}{l}\text { Intention of } \\
\text { purchase }\end{array}$ & $\begin{array}{l}\text { Brand } \\
\text { attitude }\end{array}$ & $\begin{array}{c}\text { Brand } \\
\text { information }\end{array}$ & $\begin{array}{l}\text { Information } \\
\text { reliability }\end{array}$ \\
\hline Reliability & 3.4825 & 0.72959 & 1 & & & & & & & \\
\hline $\begin{array}{l}\text { Positive } \\
\text { feelings }\end{array}$ & 3.2195 & 0.85605 & $0.336^{* *}$ & 1 & & & & & & \\
\hline $\begin{array}{l}\text { Negative } \\
\text { feelings }\end{array}$ & 2.3279 & 0.81789 & $-0.521^{* *}$ & $-0.280^{* *}$ & 1 & & & & & \\
\hline $\begin{array}{l}\text { Purchase } \\
\text { reliability }\end{array}$ & 3.1069 & 0.73098 & $0.375^{* *}$ & $0.604^{* *}$ & $-0.325^{* *}$ & 1 & & & & \\
\hline $\begin{array}{l}\text { Intention of } \\
\text { purchase }\end{array}$ & 3.2479 & 0.79472 & $0.487^{* *}$ & $0.548^{* *}$ & $-0.440^{* *}$ & $0.524^{* *}$ & 1 & & & \\
\hline Brand attitude & 3.3561 & 0.64959 & $0.445^{* *}$ & $0.448^{* *}$ & $-0.373^{* *}$ & $0.576^{* \star}$ & $0.469^{* *}$ & 1 & & \\
\hline $\begin{array}{l}\text { Brand } \\
\text { information }\end{array}$ & 2.9749 & 0.90532 & $0.226^{* *}$ & $0.516^{* *}$ & $-0.163^{* *}$ & $0.478^{* *}$ & $0.326^{* *}$ & $0.363^{* *}$ & 1 & \\
\hline $\begin{array}{l}\text { Information } \\
\text { reliability }\end{array}$ & 3.3716 & 0.58044 & $0.474^{* *}$ & $0.455^{* *}$ & $-0.440^{* *}$ & $0.599^{* *}$ & $0.493^{* *}$ & 0.546 & $0.310^{* *}$ & 1 \\
\hline & AVE & & 0.856 & 0.840 & 0.877 & 0.644 & 0.712 & 0.602 & 0.831 & 0.728 \\
\hline \multicolumn{3}{|c|}{ Conceptual reliability } & 0.959 & 0.963 & 0.966 & 0.878 & 0.904 & 0.858 & 0.951 & 0.914 \\
\hline
\end{tabular}

${ }^{* *} p<0.01$.

Table 7. Study Model goodness-of-fit exponent

\begin{tabular}{|c|c|c|}
\hline Goodness-of-fit index & Evaluation criteria & Model fitting results \\
\hline Degrees of freedom (df) & $\begin{array}{l}\text { The number of available units of information after } \\
\text { which the parameter is estimated }\end{array}$ & 469 \\
\hline Chi-square statistics & - & 4103.721 \\
\hline Probability of significance $(p)$ & - & 0.000 \\
\hline Goodness-of-fit index GFI) & $>0.9$ Excellent, $>0.8$ Good & 0.822 \\
\hline Adjusted goodness-of-fit index (AGFI) & $>0.8$ Excellent, $>0.7$ Good & 0.787 \\
\hline Root mean square residual (RMR) & Min value & 0.084 \\
\hline Normed fit index (NFI) & $>0.9$ Excellent, >0.8 Good & 0.917 \\
\hline Tucker-Lewis Index (TLI) & $>0.9$ Excellent, >0.8 Good & 0.916 \\
\hline Comparative fit index (CFI) & $>0.9$ Excellent, >0.8 Good & 0.926 \\
\hline Incremental fit index (IFI) & The closer to 1 , the better & 0.926 \\
\hline $\begin{array}{l}\text { Simplified basic compatibility index } \\
\text { (Parsimonious } \mathrm{CFI} \text { ) }\end{array}$ & $>0.7$ Excellent, $>0.6$ Good & 0.822 \\
\hline $\begin{array}{l}\text { Simple standard compliance index } \\
\text { (Parsimonious NFI) }\end{array}$ & $>0.7$ Excellent, >0.6 Good & 0.815 \\
\hline Chi-square statistics & $<0.1$ Adoption, $<0.05$ Optimal & 0.080 \\
\hline
\end{tabular}


하여 도출된 요인들로서 확인적 요인분석을 통해 요인변수들에 대 한 타당성이 입증되었다. 개념 타당성을 검증하기 위해서 적합도 를 평가지표로 goodness of fit index (GFI, 0.9이상 우수, 0.8 이 상 양호), adjusted GFI (AGFI, 0.9이상), 카이자승(적을수록 바람 직함), 카이자승에 대한 $p$ 값(0.05이상이면 바람직함)을 적용하였 으며 분석의 결과 $\chi^{2}=4103.721, \mathrm{df}=469, \chi^{2}$ 에 대한 $p$ 값 $=0.000$, GFI=0.822, AGFI=0.787, CFI=0.926, RMR=0.084, NFI(normed fit index $)=0.917$, tucker-lewis index $(\mathrm{TLI})=0.916$, Parsimonius $\mathrm{CFI}=0.822$, Parsimonius NFI=0.815, RMSEA $=0.080$ 을 나타내고 있다. 전반적인 적합도 지수중 GFI는 기준치인 0.80 을 상회하고 있 으며 자유도를 고려한 수정 GFI의 값인 AGFI는 기준치인 0.80 을 상 회하고 있고, $\mathrm{CFI}$ 값과 RMSEA값이 모두 기준치를 상회 하고 있다. 그리하여 전반적 적합도 지수들은 종합적으로 고려할 때 대체로 본 모형은 Figure 1과 같으며 수용할만한 모형임을 알 수 있다. 가설검 증의 결과를 살펴보면 긍정적 감정은 브랜드정보에 C.R 값 13.327 의 통계적으로 유의미한 정적(+)인 영향력을 주는 것으로 나타났으 며 구매의도에는 C.R 값 8.865, 정보신뢰도에는 C.R 값 8.959, 구매 신뢰도에는 C.R 값 14.345. 브랜드태도에는 C.R 값 9.387로 나타나 유의미한 정적(+)인 영향력을 확인할 수가 있었다. 이러한 결과는 긍 정적 감정이 높을수록 브랜드 정보, 구매의도, 정보신뢰도, 구매신뢰 도, 브랜트 태도는 증가하는 것으로 이해가 된다. 또한, 긍정적 감정 이 가장 높은 영향력을 주는 요인은 구매신뢰도로 나타났으며 다음 으로는 브랜드 정보로 확인되었다. 다음으로는 부정적 감정이 종속 변수에 미치는 영향력을 분석한 결과를 살펴보면 구매의도에는 C.R 값 -5.983 , 정보신뢰도에는 C.R 값 -8.098 의 통계적인 범위 내에 서 부적(-) 영향력을 확인할 수가 있었으며 구매신뢰도에는 C.R 값 -4.824 , 브랜드태도에는 C.R 값 -5.535 로 나타나 부적(-)인 영향력

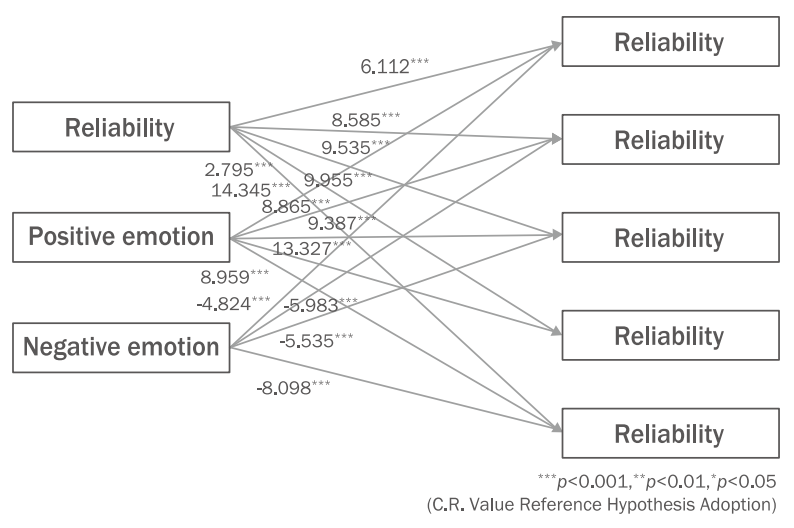

Figure 1. Study model analysis results.

The brand information C.R. value of 13.327 was found to have a statistically significant static (+) influence, with C.R. of 8.865 for purchase intent, C.R. of 8.959 for information reliability, C.R. of 14.345 for purchase reliability and C.R. of 9.387 for brand attitude. C.R., critical ratio.
을 확인할 수가 있었다. 이러한 결과는 부정적 감정이 높아질수록 구 매의도, 정보신뢰도, 구매신뢰도, 브랜드 태도는 감소한다는 것으로 해석할 수가 있다. 부정적 감정이 가장 높은 영향을 주는 요인은 정 보신뢰도로 파악이 되었으며 다음으로는 구매의도, 브랜드 태도 순 으로 확인되었다. 신뢰성이 영향력을 미치는 부분에 대한 결과를 살 펴보면 신뢰성은 브랜드정보에 C.R값 2.795의 유의미한 정적(+)인 영향력을 주었으며 구매의도에는 C.R값 8.585의 정적(+) 영향을 주 었다. 그리고 정보신뢰도에는 C.R 값 9.955, 구매신뢰도에는 C.R 값 6.112, 신뢰성에는 C.R 값 9.535로 나타나 유의미한 정적(+) 영향력 을 확인할 수가 있었다. 이러한 분석의 결과는 Table 7과 같으며 신 뢰성이 증가하게 되면 브랜드 정보, 구매의도, 정보신뢰도, 구매신뢰 도, 브랜드태도가 높아진다는 것으로 이해가 되며 신뢰성이 정보신 뢰도에 가장 큰 영향을 주었으며 다음으로는 브랜드 태도로 확인되었 다. 본 분석의 결과를 정리하면 긍정적 감정은 구매신뢰도에 가장 큰 영향력을 주며 부정적 감정은 정보신뢰도, 신뢰성은 정보신뢰도에 가장 높은 영향력을 주었다.

\section{Conclusion}

본 연구는 온라인 화장품 정보가 브랜드 신뢰 및 온라인에서의 지 속적 구매행동에 미치는 영향을 알아보고자 온라인 화장품 구매 경 험이 있는 일반 성인 여성과 남성을 대상으로 화장품 정보에 대한 구 매 신뢰성, 구매의도, 브랜드 태도, 브랜드 정보, 정보 신뢰도에 대 해 신뢰성, 긍정적 감정, 부정적 감정 등을 분석을 실시 하였다. 이 에 대한 결과는 다음과 같다. 첫째, 온라인 화장품 정보에 대한 긍정 적 감정이 높을수록 브랜드정보, 구매의도, 정보신뢰도, 구매신뢰도, 브랜드 태도가 증가 하는 것으로 나타났다. 긍정적 감정은 온라인에 서의 화장품 관련 정보를 스스로 찾아보고, 이러한 정보를 이해하면 서 신뢰하는 것을 말한다. 이러한 긍정적 감정은 구매신뢰도에 가장 큰 영향을 주었는데, 구매신뢰도는 온라인 화장품 정보인 브랜드의 광고에 호감을 느끼며 제품의 효능/효과에 대한 사용후기를 찾아 보 고, 이러한 후기를 신뢰하며 이러한 본인의 경험을 권유하는 것을 말 한다. 또한 긍정적 감정은 구매의도에 두번째로 많은 영향을 주었는 데, 이는 온라인 화장품 정보 중 성분 및 효능/효과를 찾아보고, 판매 가격을 비교하며 더욱이 사용자 후기를 비교함으로써 온라인 화장품 정보를 통해 구매의도에 긍정적인 영향을 주는 것이다. 둘째, 온라인 화장품 정보에 대한 부정적 감정으로 나타나는 내용으로 온라인 화장 품 정보에 대한 신뢰 정도와 온라인에서 화장품 정보를 탐색하는 행 위에 대한 즐거움, 그리고 온라인 화장품 구매에 대한 감정을 특정한 결과 이러한 항목에서 부정적인 감정이 높아질수록 구매의도, 정보 신뢰도, 구매신뢰도, 브랜드 태도는 감소한다는 것으로 나타났다. 이 러한 부정적 감정에 가장 높은 영향을 주는 요인으로 온라인 정보신 뢰도로 파악이 되었는데, 정보신뢰도는 화장품 브랜드의 광고에 나 
타나는 성분이나 효능에 대한 내용에 대해 신뢰도가 낮게 나타나는 것으로 이는 구매신뢰도에도 영향을 주고 있는 것으로 나타났다. 셋 째, 온라인 화장품 정보에 대한 신뢰성 분석 결과는 신뢰성이 증가하 게 되면 브랜드 정보, 구매의도, 정보신뢰도, 구매신뢰도, 브랜드태 도가 높아진다는 것으로 나타났으며, 신뢰성이 정보신뢰도에 가장 큰 영향을 주었으며 다음으로는 브랜드 태도로 확인되었다. 정보신 뢰도는 온라인 화장품 브랜드에 대한 광고 시 보여주는 성분이나 효 능/효과에 대해 신뢰성을 보이며, 이를 바탕으로 사용자의 후기를 찾 아 보고 이러한 사용 후기에 대한 신뢰를 갖는 것으로 나타났다. 이 상의 결과를 볼 때 온라인 화장품 정보에 대한 신뢰성과 긍정적 감정 이 높을수록 브랜드 신뢰도와 온라인에서의 지속적 구매에 매우 큰 영향을 주는 것을 알 수 있으므로 다음과 같은 온라인 화장품 정보 관 리에 대한 시사점을 제공하고자 한다. 온라인 화장품 브랜드 정보 제 공 시 마케터들은 온라인 및 모바일 환경과 사용자의 특성을 감안하 여 브랜드 광고의 제품, 모델 등의 이미지에 대한 고민을 해야 하며, 광고 외 제품에 대한 주요 성분 및 효능/효과에 대한 내용을 효과적 으로 전달 할 수 있는 방안에 대해 내용이나 컨텐츠를 적극적으로 제 안하고 관리해야 할 것이다. 또한 사용자 후기에 대한 정보가 신뢰성 을 높이고, 긍정적 감정 형성에 주요한 요인으로 온라인에서 화장품 정보 노출 시 사용후기에 대한 보다 적극적인 관리 및 대안 제시가 필 요하다. 반면 부정적 감정 요소에 대해서는 객관적이고 신뢰성 있는 화장품 브랜드 정보 제공 방안에 대해 지속적인 관심과 관리가 필요 하다. 본 연구는 조사 대상자를 온라인에서 화장품 구매 경험이 있는 대상자로 한정하였고, 온라인 화장품 정보를 화장품 구매 시 고려하 는 중요성과 구매 시 성향으로 진행 하여 제한성을 갖고 있다. 후속 연구로 온라인 화장품 정보에 대한 신뢰성과 긍정적 감정을 높일 수 있는 요소들인 디자인, 색채, 페이지 구성 등 현재 브랜드에서 운영 중인 구체적인 브랜드 사례를 비교 연구가 필요할 것으로 사료 된다.

\section{Author's contribution}

BSK, JML and SA designed overall studies and wrote the manuscript together. BSK and SA analyzed the data. All authors read and confirmed the final version of manuscript.

\section{Author details}

Byoung Su Kim (Graduate Student), Department of Cosmetics Engineering, Konkuk University, 120 Neungdong-ro, Gwangjin-gu, Seoul 05029, Korea and (Team Manager), Masstige Strategic \& Planning Team, LG Household \& Health Care, LG Science Park E12, 6F. 70, Magokjungang 10-ro, Gangseo-gu, Seoul 07795, Korea; Jung Min Lee (CEO), Nature Blue, Inc., \#508, Techno Cube, 174-1 Songdo-dong, Yeonsu-gu, Incheon-si 21984, Korea; and Sungkwan An (Professor), Department of Cosmetics
Engineering, Konkuk University, 120 Neungdong-ro, Gwangjin-gu, Seoul 05029, Korea.

\section{References}

Anderson JC, Gerbing DW. Structural equation modeling in practice: a review and recommended two-step approach. Psychological Bulletin, 103: 411-423, 1988.

Cho IC, Eom WY. A study on the effects of confidence and community loyalty on the purchase in relation to online travel community characteristics. International Journal of Tourism Management and Sciences, 27: 397-412, 2012.

Fornell C, Laker DF. Evaluating structural equations models with unobservable variables and measurement error. Journal of Marketing Research, 18: 39-50, 1981.

Jeong HY. Job type for recruitment, job function change and education direction in the fashion industry along with the growth of the online market. Journal of the Korea Fashion \& Costume Design Association, 22: 75-87, 2020.

Jeong SH. Purchasing behavior for skin care products by distribution channel. Asian Journal of Beauty and Cosmetology, 16: 545-554, 2018.

Joh YH. The effect of the customer trust with cause the information of the commodity and seller on the purchasing intention in internet open market. The Business Studies, 8: 189-210, 2007.

Ju EL, Ahn HS. A study on purchasing behavior of cosmetic consumers on the internet. Asian Journal of Beauty and Cosmetology, 8: 239-253, 2010.

Kang LJ, Sin JB. An analysis on the determinants of consumers' decision to purchase cosmetics by their consumption propensity. Journal of Consumption Culture, 9: 83-103, 2006.

Kim CG. The structural relationship among influential factors, satisfaction and customer loyalty on internet shopping mall. Journal of Korean Regional Development, 11: 51-86, 2012.

Kim JA, Oh YK. Purchase behavior and satisfaction of onlineonly brand cosmetics. Asian Journal of Beauty and Cosmetology, 16: 32-41, 2018.

Kim KJ, Han HS. Marketing strategies and consumer recognition of medical cosmetics. Asian Journal of Beauty and Cosmetology, 16: 569-578, 2018. 
Kwon OH, Lee JM. The impact of the characteristics of the online communities of cosmetic brands on the relation quality between consumers and the brands. Journal of the Korean Society of Cosmetology, 24: 67-75, 2018.

Lee $\mathrm{MH}$, Kim HJ. A study on cosmetics purchase behavior and consumer dissatisfaction at internet shopping mall. Journal of the Korea Fashion \& Costume Design Association, 8: 87-100, 2006.

Moon SI. Regulatory reform proposal for deregulating the selling of insurance goods on online platform. Business Law Review, 35: 21-41, 2021.

Nunnally JC. Psychometric theory (2nd ed). McGraw-Hill, USA, pp405-437, 1978.

Park IJ, Kim JE, Relationships among shopping orientation, shopping-mall characteristics, consumer satisfaction, and loyalty in online market of cosmetics. The Research Journal of the Costume Culture, 16: 696-708, 2008.

Son JY, Eo SH. An effect of directiveness of online transmissive information when purchasing cosmetics online on purchase intention of consumer. Journal of the Korean Society of Cosmetology, 14: 929-945, 2008.

Sung DG, Lee HB, Lee SC, Jang CY, Choe IG. The use of statistical techniques easy to understand social phenomena for research and writing research papers SPSS. DaeMyeong, Daegu, pp103-111, 2011.

Van de Ven AH, Ferry DJ, Measuring and assessing organizations. New York, Wiley, pp52-88. 1980. 


\section{국문초록}

\section{온라인 화장품 정보가 브랜드 신뢰 및 온라인에서의 지속적 구매의도에 미치는 영향}

김병수 ${ }^{1,2}$, 이정민 ${ }^{3}$, 안성관 ${ }^{1 *}$

${ }^{1}$ 건국대학교 화장품공학과, 서울, 한국

${ }^{2} \mathrm{LG}$ 생활건강 Pre. 영업지원팀, 서울, 한국

${ }^{3}$ (주)네이쳐블루, 인천광역시, 한국

목적: 본 연구는 온라인 쇼핑 화장품 브랜드 관련 정보에 대한 구매의도, 인식변화등 구매와 브랜드간의 심층적 연구를 통해 온라인 에서의 화장품 정보 신뢰 및 지속적 구매행동에 미치는 영향에 대해 분석하고자 한다. 방법: 설문조사는 최근 6 개월간 온라인을 통 해 화장품을 구입한 경험이 있는 사용자를 대상으로 온라인 설문을 통해 총 1,300 부가 배부되었고 불성실한 응답자, 결측 값을 제 외하고 총 1,197 부를 최종 분석하였으며, 통계처리는 데이터 코딩 과정을 거친 다음 SPSS(Statistical Package for Social Science) 22.0과 Amos 21.0을 사용하여 실증 분석을 실시하였다. 결과: 온라인 화장품 정보에 대한 브랜드 신뢰 및 지속구매를 위한 구매의 도 관한 연구로 8개의 중요 변수인 신뢰성, 긍정적 감정, 부정적 감정, 구매신뢰도, 구매의도, 브랜드 태도, 브랜드 정보, 정보신뢰 도로에 대한 관계를 분석 하였다. 결과로 긍정적 감정에 대한 결과로 긍정적 감정이 높을수록 브랜드 정보, 구매의도, 정보신뢰도, 구매신뢰도, 브랜드 태도는 증가하는 것으로 나타났다. 부정적 감정이 높아질수록 구매의도, 정보신뢰도, 구매신뢰도, 브랜드 태도 는 감소한다는 것으로 해석할 수가 있다. 부정적 감정이 가장 높은 영향을 주는 요인은 정보신뢰도로 파악이 되었다. 신뢰성 분석의 결과는 신뢰성이 증가하게 되면 브랜드 정보, 구매의도, 정보신뢰도, 구매신뢰도, 브랜드태도가 높아진다는 것으로 나타났으며, 신 뢰성이 정보신뢰도에 가장 큰 영향을 주었다. 결론: 온라인 화장품 브랜드 정보 제공시 마케터들은 온라인 및 모바일 환경과 사용자 의 특성을 감안하여 브랜드 광고에 대한 고민을 해야 하며, 광고외 브랜드 제품에 대한 주요 성분 및 효능/효과에 대한 내용을 효과 적으로 전달 할 수 있는 방안에 대해 내용이나 컨텐츠를 적극적으로 제안하고 관리해야 하며, 객관적이고 신뢰성 있는 화장품 브랜 드 정보 제공 방안에 대해 지속적인 관심과 관리가 필요하다.

핵심어: 브랜드 정보, 신뢰, 온라인 구매, 온라인 화장품 정보, 화장품

\section{참고문헌}

강이주, 신자빈. 소비성향에 따른 화장품 소비자의 구매결정요인 분석. 소비문화연구, 9: 83-103, 2006.

김진아, 오윤경. 온라인 전용 브랜드 화장품의 구매 행태와 만족도. 아시안뷰티화장품학술지, 16: 32-41, 2018.

김정권. 인터넷쇼핑몰에서의 영향요인, 만족 및 고객충성도의 구조적 관계. 지역발전연구, 11: 51-86, 2012.

김경진, 한효선. 메디컬 화장품의 마케팅 전략과 소비자 인식도. 아시안뷰티화장품학술지, 16: 569-578, 2018.

권오혁, 이정민. 화장품 브랜드 온라인 커뮤니티 특성이 소비자-브랜드 관계품질에 미치는 영향. 한국미용학회지, $24:$

$67-75,2018$.

박은주, 김지은. 화장품 온라인 시장에서 쇼핑 성향, 쇼핑몰 특성, 소비자 만족, 충성도의 관계. 복식문화연구, 16: $696-$

708, 2008.

문상일. 온라인플랫폼에서의 보험상품판매규제와 법제 개선방안. 기업법연구, 35: 21-41, 2021.

손지연, 어숙희. 화장품 온라인 쇼핑시 온라인 구전 정보의 방향성이 소비자 구매의도에 미치는 영향. 한국미용학회지,

14: 929-945, 2008.

성도경, 이환범, 이수창, 장철영, 최인규. 알기쉬운 통계기법의 활용: 사회현상 조사분석 및 연구논문 작성을 위한 SPSS.

대명, 대구, pp103-111, 2011.

이명희, 김현정. 인터넷 쇼핑몰에서의 화장품 구매행동과 소비자불만에 관한 연구. 한국의상디자인학회지, 8: 87-100, 
2006.

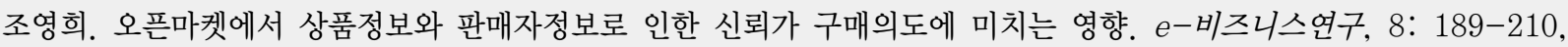
2007.

조인철, 엄완용. 온라인 여행 커뮤니티의 특성에 따른 소비자의 신뢰와 충성도가 구매결정에 미치는 영향. 관광연구, 27 : 397-412, 2012.

정선희. 유통채널별 기초화장품 구매행동. 아시안뷰티화장품학술지, 16: 545-554, 2018.

정화연. 온라인 시장의 성장에 따른 패션산업 내 채용직종 및 직무 변화 및 교육방향. 한국의상디자인학회지, 22: 75-87. 2020.

주은령, 안홍석. 인터넷 소비자의 화장품 구매행태에 관한 연구. 아시안뷰티화장품학술지, 8: 239-253, 2010. 


\section{中文摘要}

\section{在线化妆品信息对品牌信任和在线持续购买意向的影响}

金炳壽 ${ }^{1,2}$, 李貞旼 $^{3}$, 安晟官 ${ }^{1 *}$

建国大学化妆品学科, 首尔, 韩国

${ }^{2} \mathrm{LG}$ 生物健康营业部, 首尔, 韩国

${ }^{3}$ (株) Nature Blue，仁川，韩国

目的: 本研究旨在通过对品牌之间的深入研究, 分析在线化妆品信息、品牌信任和持续购买行为的影响, 包括化 妆品品牌的购买意向和在线购物感知的变化。方法: 在过去六个月内, 共有 1300 项调查在网上发布, 不包括不忠 的受访者和缺失值, 并使用IBM社会科学统计软件包 (SPSS) 22.0和Amos 21.0进行统计处理。结果: 本研究分 析了可靠性、积极情绪、消极情绪、购买可信度、购买意图、品牌态度、品牌信息和信息可信度八个变量之间 的关系。结果表明, 积极情绪越高, 品牌信息、购买意愿、信息可靠性、购买可靠性和品牌态度越高。研究结 果还表明, 消极情绪越高, 购买意愿、信息可靠性、购买可靠性和品牌态度越低。负性情绪的影响因素主要是 信息可靠性。可靠性分析结果表明, 较高的可靠性增加了品牌信息、购买意愿、信息可靠性、购买可靠性和品 牌态度 ; 可靠性对信息可靠性的影响最大。结论: 在提供在线化妆品品牌信息时, 营销人员需要根据在线和移动 环境以及用户特征制定品牌广告策略, 积极提出和管理能够有效传达非广告品牌产品主要成分和效果的内容和 广告, 持续提供客观可靠的化妆品品牌信息。

关键词: 品牌信息, 化妆品, 在线化妆品信息, 在线购买, 信任 